\title{
A revisão quinquenal dos contratos de concessão do Serviço Telefônico Fixo Comutado (STFC): período 2011-2015*
}

Telecommunication Sector Update

The Quinquennial Review of the Switched Fixed Telephone Service (STFC) Public Regime Agreements for the Years 2011-2015

Submetido(submitted): 25 de fevereiro de 2011

Parecer(revised): $1^{\circ}$ de março de 2011

Marina Cruz Vieira Villela*

Aceito(accepted): 8 de abril de 2011

Informe setorial

Atualizado até janeiro de 2011

\section{Introdução}

Os atuais contratos de concessão do Serviço Telefônico Fixo Comutado Destinado ao Uso do Público em Geral (STFC), nas modalidades Local, Longa Distância Nacional (LDN) e Longa Distância Internacional (LDI), possuem vigência até 31 de dezembro de 2025, com revisões contratuais previstas para cada quinquênio, ocasião em que poderão ser estabelecidos pela Anatel novos condicionamentos e novas metas de universalização e de qualidade, tendo em vista as condições vigentes à época.

O $\S 1^{\circ}$, da Cláusula 3.2, dos contratos de concessão, determina que, para a realização de tais alterações, seja efetuada consulta pública vinte e quatro meses antes dos prazos de revisão fixados nos contratos.

No entanto, em 24 de dezembro de 2008, o Ministério das Comunicações protocolizou o Ofício n. 321/2008/MC, sugerindo que fosse avaliada a conveniência e a oportunidade de se adiar a data de início da publicação da consulta pública prevista na Cláusula 3.2, relativa ao quinquênio encerrado em 31 de dezembro de 2010, em virtude do momento

\footnotetext{
*Atualização do informe homônimo constante da RDET 1(1): 233-255.

*Pós-graduada em Regulação de Telecomunicações pela Universidade de Brasília. Especialista em Regulação de Serviços Públicos de Telecomunicações da Agência Nacional de Telecomunicações (Anatel).
} 
de importantes transformações regulatórias vivenciado pelo setor de telecomunicações, o que, após aceitação pelas concessionárias e pela sociedade por meio de consulta pública, foi efetivado a partir da assinatura de termos aditivos.

Em 26 de março de 2009, o Conselho Diretor da Anatel, em sua 516 Reunião, aprovou a realização de consulta pública pelo prazo de 63 dias e a realização de cinco audiências públicas nas cidades de Manaus/AM, Salvador/BA, Rio de Janeiro/RJ, São Paulo/SP e Florianópolis/SC, para apresentação da matéria e debate com a sociedade civil. Decidiu, ainda, a realização de sessão, em Brasília, no Distrito Federal, para deliberação, pelo Conselho Diretor, sobre a proposta final de revisão dos contratos de concessão, onde foi dada oportunidade de debate oral aos interessados na decisão.

\section{Da consulta pública}

A Consulta Pública n. 11, de 27 de março de 2009, com a proposta de revisão dos contratos de concessão, foi publicada no Diário Oficial da União de 31 de março de 2009 e ficou disponível inicialmente para apresentação de contribuições até a data de $1^{\circ}$ de junho de 2009, pela Internet, e 28 de maio de 2009, para as manifestações através de carta, fax ou correspondência eletrônica, sendo que este prazo foi estendido até 22 de junho de 2009 para manifestações no Sistema de Consulta Pública da Agência, e 18 de junho de 2009 para manifestações via carta, fax ou email, conforme Despacho n. 3.618/2009-CD, de 27 de maio de 2009, publicado no Diário Oficial da União em 29 de maio de 2009.

Muitas das alterações contidas na proposta encaminhada à consulta pública visaram apenas ao ajuste de redação ou de terminologia dos contratos de concessão. No Capítulo II, que trata da área de prestação do serviço, foi proposta alteração para consolidação dos contratos de concessão regionalizados em um único contrato de prestação por prestadora. No capítulo XII, sobre o reajustamento de tarifas, foi incluído o Acesso Individual Classe Especial (AICE) nos cálculos. No que tange aos direitos e garantias dos usuários e demais prestadores, foi explicitada a garantia às demais prestadoras de acesso às redes de telecomunicações da concessionária, em condições não discriminatórias, isonômicas e coerentes, 
além da menção ao Decreto n. 6.523, de 31 de julho de 2008, sobre Serviço de Atendimento ao Consumidor, adequando-se as cláusulas sobre obrigações das concessionárias ao disposto no decreto. No Capítulo XVI, a competência para requerer informações das concessionárias foi ampliada no texto proposto, pois tal competência antes era restrita à área da Anatel responsável pela fiscalização e agora passaria a ser da Anatel como um todo. Além disso, foi proposto que a concessionária disponibilizasse trimestralmente a relação de bens e serviços adquiridos. No Capítulo XVII, 'Das Obrigações e Prerrogativas da Anatel', foi incluída possibilidade da Agência determinar o cancelamento de alienação realizada ou reposição equivalente, quando contrários à legislação, normas e regulamentos. Sobre bens vinculados à concessão, foi incluído parágrafo que especifica que as atividades e processos necessários à prestação do STFC integram o acervo de bens vinculados à concessão. $\mathrm{O}$ capítulo sobre conselho de usuários foi adequado ao Regulamento de Usuários em vigor. Finalmente, no Anexo 1, foi incluído item relativo a infraestrutura e equipamentos decorrente de obrigações de universalização relativas ao backhaul.

Foram apresentadas mais de seiscentas contribuições à proposta de texto dos contratos de concessão, abarcando prestadoras de serviços de telecomunicações, órgãos de defesa do consumidor, entidades de classe, entidades governamentais e usuários, sendo que as concessionárias foram responsáveis por $40 \%$ das contribuições, os órgãos de defesa do consumidor, por $20 \%$, e os usuários, em torno de $10 \%$.

Praticamente todos os capítulos receberam contribuições, que estão disponíveis, assim como o texto submetido a consulta pública, no sítio eletrônico da Anatel.

\section{Das audiências públicas}

Foram realizadas seis audiências públicas entre os dias 28 de abril e 27 de maio de 2009, com um total de cento e noventa e nove participantes, nas quais foram apresentados e debatidos os conteúdos das Consultas Públicas ns. 11, 13 e 14, respectivamente sobre Revisão dos Contratos de Concessão, Plano Geral de Metas de Universalização e Plano Geral de Metas de Qualidade. 
Em todas as audiências a Anatel apresentou noções conceituais sobre a revisão dos contratos de concessão, incluindo abrangência e escopo das alterações, principais passos, cenário atual, visão estratégica e temas relevantes, conforme exposto no informe precedente sobre revisão dos contratos de concessão, na RDET 1(1): 233-255, de 2009. Em seguida, os representantes da Agência apresentaram as propostas de alteração do texto contratual.

A primeira audiência pública ocorreu em Manaus, no Auditório da Suframa, nos dias 28 e 29 de abril e contou com vinte e oito participantes, onze manifestações orais e duas manifestações escritas. As manifestações escritas foram de representante da Procuradoria Federal e de servidor da Anatel, sendo que o primeiro sugeriu a inclusão de cláusula contratual que obrigasse as concessionárias a incluírem em seu sítio eletrônico telefone, endereço e email para contato com órgãos oficiais, enquanto o segundo sugeriu a inclusão de obrigação para atualizar a estrutura de rede.

As manifestações orais, por sua vez, originaram-se de representantes de municípios do Estado do Amazonas, de São Paulo e de Olivença, de representante da Central Única Comunitária e do Conselho Regional da Telemar, de servidores da Anatel, de representante da Agência Reguladora do Acre e de representantes de prestadoras de telecomunicações autorizadas. Em geral, foi pedida uma melhor divulgação das audiências públicas e ressaltada a precariedade das telecomunicações em geral nos municípios do Amazonas, a dificuldade de atendimento a determinadas localidades, haja vista as peculiaridades da região, a necessidade de alteração da legislação para atendimento da população isolada e de utilização dos recursos do FUST, a necessidade de criação de tarifa social para baixa renda, bens reversíveis e cláusulas pró-competição.

A segunda audiência pública foi realizada no auditório do Escritório Regional da Anatel, de Salvador, nos dias 7 e 8 de maio de 2009. Ela contou com apenas nove participantes e quatro manifestações orais de representante da Federação das Indústrias da Bahia, de representante da Federação Interestadual dos Trabalhadores em Telecomunicações (FITTEL) e de servidor da Anatel. Os temas levantados consistiram na indexação das tarifas de telefonia ao IGP-DI, a necessidade de haver maior preocupação com os trabalhadores em telecomunicações, a necessidade de se fomentar a 
banda larga para todos e a necessidade de manutenção da assinatura básica, em face da permanente disponibilização do serviço.

A audiência pública de São Paulo, realizada nos dias nos dias 13 e 14 de maio de 2009, no auditório Horácio Lafer, do Ministério da Fazenda, teve quarenta e nove participantes, onze manifestações escritas e dez manifestações orais de autoria de auditor independente, representantes de prestadoras de telecomunicações, de entidades de defesa do consumidor e da Folha de São Paulo. O teor das manifestações versou sobre o foco das alterações no interesse público e no saneamento de precariedades, a dosimetria das multas, a adequação de novos condicionamentos de qualidade e universalização ao que o cidadão necessita, a reversibilidade do backhaul e a possibilidade de indenização da parte privada do investimento feito pelas operadoras em sua rede para atender contratos privados, as formas de superação das limitações impostas pela LGT para que as concessionárias vivenciem a convergência dos serviços, a ausência de metas de competição nos contratos de concessão, a competição em banda larga, a desagregação de redes e o modelo de custos.

Outro tema bastante discutido na audiência pública de São Paulo foi a universalização do STFC em face dos valores cobrados pela assinatura básica, pelos quais a maior parte da população brasileira não pode pagar mensalmente, assim como as tarifas de longa distância. Nesse sentido, questionou-se se o AICE teve adesão suficiente.

Os bens reversíveis também foram questionados: pertencem às concessionárias ou ao Estado? Como deve-se dar a substituição de tais bens?

A real função das audiências públicas também foi questionada, tendo em vista a quantidade de material produzido pela Anatel e o pouco tempo para que a sociedade se inteirasse dela e contribuísse. Em que medida o instrumento de consulta pública cumpre sua função? Ademais, como garantir transparência ao cumprimento das metas impostas aos prestadores por parte da agência reguladora?

Nos dias 18 e 19 de maio, ocorreu, no Espaço Cultural da Anatel, a audiência pública de Brasília, que teve dezesseis participantes, uma manifestação escrita e duas manifestações orais. Um usuário indagou acerca da política da Anatel para manutenção dos contratos específicos fora da Área de Tarifa Básica com os mesmos serviços prestados atualmente. O representante da FITTEL criticou a atuação da Anatel, indicando que as 
reclamações de assinantes não são devidamente tratadas, e que é necessário haver maior investimento em fiscalização e aplicação correta dos recursos do FUST. Por sua vez, um representante de entidade de classe de prestadoras autorizatárias de telecomunicações indagou como a Agência enxergava a necessidade de competição.

A audiência pública de Florianópolis ocorreu nos dias 21 e 22 de maio de 2009, no Auditório da Celesc, e contou com setenta e dois participantes, duas manifestações escritas e seis manifestações orais. De um modo geral, as manifestações orais e escritas foram de prefeitos ou representantes de prefeituras de municípios de Santa Catarina e tiveram como foco o atendimento fora da área de tarifa básica.

A última audiência pública ocorreu no Rio de Janeiro, nos dias 26 e 27 de maio de 2009, no Auditório da Ancine, e teve vinte e cinco presentes, que apresentaram oito manifestações escritas e oito manifestações orais, de autoria de usuários, representantes do Clube de Engenharia e de prestadoras de telecomunicações. Além de comentário acerca da necessidade de melhor divulgação das audiências públicas, a mesa foi indagada acerca do prazo para implementação do modelo de custos, sobre a equivalência das trocas de metas de universalização e dos bens reversíveis, sobre desagregação do acesso das redes, sobre a possibilidade de se evitar subsídios cruzados ou compartilhar ganhos de eficiência com a crescente convergência entre os serviços e as redes que os suportam, sobre a evolução do STFC e o reflexo desta evolução nos bens reversíveis e sobre um possível conflito com o serviço de comunicação multimídia. Falou-se também sobre a importância da convivência do serviço em regime público com outros serviços, sobre a enorme carga tributária brasileira, a quantidade de reclamações contra prestadoras de telecomunicações no PROCON, o papel da Anatel e a necessidade de uma adequação na remuneração de redes móveis e fixas. Houve muitas reclamações sobre o tema do atendimento, especialmente sobre a manutenção de rede em área rural, a satisfação do assinante com o atendimento e a quantidade/qualidade de informação na oferta dos serviços, o que demandaria melhor fiscalização por parte da Anatel. Houve manifestação também sobre as dificuldades de atendimento por deficientes auditivos. 


\section{Da deliberação pelo Conselho Diretor}

No dia 24 de novembro de 2010, o Conselho Diretor realizou, no Espaço Cultural da Anatel, uma sessão pública para deliberar sobre a proposta de revisão dos contratos de concessão de STFC, relatada pelo conselheiro João Rezende. Participaram da sessão pública cento e quarenta e uma pessoas, sendo que oito apresentaram manifestação oral.

A primeira modificação no texto deu-se na definição do Serviço Telefônico Fixo Comutado, constante da Cláusula 1.2, para incluir a expressão "na forma da regulamentação" ao final da definição. Essa alteração somente não foi acatada pela conselheira Emília Ribeiro, que entendeu que tal modificação já havia sido proposta quando da alteração do Plano Geral de Outorgas, em 2008, que foi rejeitada pelo Ministério das Comunicações.

A segunda alteração contratual se refere à consolidação em um único contrato de prestação do serviço por prestadora e não mais um contrato para cada setor do Plano Geral de Outorgas. Neste sentido, a fim de garantir que o plano básico das concessionárias continue sendo regionalizado, o parágrafo único da Cláusula 11.1 também foi alterado para estabelecer que o plano básico será único em cada setor do PGO e não mais para toda a área de prestação do serviço.

$\mathrm{Na}$ Cláusula 3.3, foi inserida a possibilidade de adimplir parte do pagamento do ônus contratual de $2 \%$ das receitas da concessão com o cumprimento de novas obrigações de universalização definidas em Plano Geral de Metas de Universalização, aprovado por Decreto Presidencial. A conselheira Emília Ribeiro também votou contra esta alteração, por entender que as metas de universalização somente podem ser financiadas pela exploração eficiente do serviço ou pelos recursos do Fundo de Universalização dos Serviços Telecomunicações. O voto vencedor se baseou no argumento de que a definição do valor do ônus contratual é de competência da Anatel, de modo que a Agência pode definir que o adimplemento desse ônus seja realizado por meio do cumprimento de obrigações.

Ainda sobre o ônus contratual, foi definido que as receitas de interconexão, de prestação, utilidade ou comodidade (PUC), de serviços adicionais e de receitas operacionais estão incluídas no montante para o 
cálculo do ônus da concessão. Esta alteração causou indignação por parte das concessionárias, que defenderam que se trataria de uma alteração de cláusula econômica, que não seria possível em sede de revisão contratual.

No capítulo sobre continuidade, foi alterado o parágrafo único da Cláusula 7.1, que dispõe que não será considerada violação da continuidade a interrupção circunstancial do serviço decorrente de situação de emergência. A partir da vigência dos novos contratos, a situação de emergência será considerada interrupção excepcional, e não mais circunstancial, e também ficará assegurado, na forma da regulamentação e do Código de Defesa do Consumidor, o direito do usuário à obtenção de crédito proporcional ao tempo em que o serviço ficou indisponível e à eventual devolução de valores pagos indevidamente.

O Capítulo IX, que traz as regras sobre suspensão do serviço por inadimplência e a pedido do assinante, teve suas cláusulas alteradas apenas para substituir os termos desligamento, interrupção e bloqueio por suspensão, que é o termo correto para as situações apresentadas.

$\mathrm{O} \S 4^{\circ}$, da Cláusula 11.2, sobre planos alternativos, foi alterado para permitir que tais planos sejam ofertados ao público em geral antes da homologação pela Anatel.

Quanto ao documento de cobrança do STFC, foi vedada a inclusão de qualquer valor que não decorra exclusivamente da prestação do serviço sem a expressa autorização do assinante. Antes, tal vedação incluía apenas serviços de valor adicionado.

Ainda sobre este tópico, foi definido que a concessionária deverá fornecer aos assinantes o detalhamento do documento de cobrança em todos os seus planos, de forma gratuita, sempre no seu sítio eletrônico na internet e, em meio impresso, mediante solicitação, periodicamente com frequência igual ou superior a um mês. Inicialmente o relator havia proposto que o detalhamento impresso do documento de cobrança deveria acontecer sempre de forma independente de solicitação, no que foi acompanhado pela conselheira Emília Ribeiro. O conselheiro Jarbas Valente propôs a redação vencedora, no que foi inicialmente acompanhado pelo presidente da Anatel, e em seguida, após intervalo, pelos demais conselheiros. A fundamentação consistiu em reduzir o impacto ambiental e ao mesmo tempo garantir que o consumidor possa, mediante uma única solicitação, ter o detalhamento em um único mês ou permanentemente, se assim o desejar. 
Foi eliminado o $\S 1^{\circ}$, da Cláusula 14.1, que restringia a participação das concessionárias ou de suas controladas e coligadas no mercado de TV a Cabo, sendo que a conselheira Emília Ribeiro foi voto vencido neste item. No entanto, a Lei do Cabo ainda impõe limitações para atuação das concessionárias de telecomunicações neste mercado (art. $7^{\circ}$, II e art. 15, caput, da Lei 8.977, de 6 de janeiro de 1995).

Outra alteração polêmica foi a possibilidade de fiscalização sem notificação prévia ou a presença de representante da empresa fiscalizada em casos em que o sigilo seja necessário para garantir a eficácia da apuração, assegurado à concessionária o acesso ao relatório correspondente após o término da diligência.

As regras de atendimento ao usuário foram alteradas para adequação ao decreto do serviço de atendimento ao consumidor, incluindo o atendimento presencial de usuários.

Quanto aos bens reversíveis, após impasse por divisão de votos no Conselho Diretor da Anatel, a decisão unânime foi a de manter praticamente o mesmo procedimento hoje adotado, em que são submetidos ao controle os bens não só das concessionárias, mas também de suas controladas e coligadas. Para alienação de tais bens, é exigida a anuência prévia da Anatel.

Além dessas alterações e outras de natureza formal, também foi incluída a previsão de liberdade tarifária nas chamadas de longa distância internacional.

A sessão pública teve mais de dez horas de duração.

\section{Do adiamento da assinatura dos contratos de concessão}

Em 16 de dezembro de 2010, teve início consulta pública pelo prazo de 10 dias para discussão do adiamento da assinatura dos contratos de concessão do dia 31 de dezembro para 2 de maio de 2011. A motivação para este adiamento foi a de se conseguir tempo adicional para que o Governo Federal e as empresas negociassem os pontos polêmicos do Plano Geral de Metas de Universalização (PGMU), anexo aos contratos de concessão. Em troca deste prazo adicional, as concessionárias concordaram em renunciarem às ações movidas no Judiciário contra o Plano Geral de Metas de Universalização e a revitalização da Telebras, parte integrante do Plano Nacional de Banda Larga. 
O principal ponto de polêmica na discussão do PGMU consiste no custo e nas formas de financiamento das metas de universalização, que a Anatel avalia em $\mathrm{R} \$ 2,11$ bilhões e as operadoras, em $\mathrm{R} \$ 12$ bilhões. As outras duas discussões giram em torno do conceito de backhaul e do atendimento de áreas rurais, cujo custo não foi apresentado pela Agência.

Os termos aditivos com o adiamento da assinatura dos contratos foram assinados no dia 28 de dezembro de 2010. 